\title{
Vacinas: Negócio de Estado?
}

\author{
Vaccines: State Business?
}

\section{Cláudio Tadeu Daniel-Ribeiro ${ }^{1}$}

DANIEL-RIBEIRO, C. T. Vaccines: State Business? Cad. Saúde Públ., Rio de Janeiro, 11 (1): 137-141, Jan/Mar, 1995.

In spite of the expectation that the development of vaccines would help in the control of some of the main transmissible diseases in Brazil, which are responsible for a large share of endemic illness in the country, efficient and safe vaccines against no less serious contagious diseases are available, yet underutilized. The reason is simple: some vaccines are not included in the National Immunization Program (PNI) and are thus not the object of government campaigns. Despite the competence with which the National Health Foundation has acted - through the $P N I$ - in reducing prevalence of diseases such as diphteria, whooping cough, measles, and polio, lack of information and prejudice make several vaccines inaccessible to a major share of the Brazilian population. Since the government - through its vaccination campaigns - exerts the most important influence on public opinion in this area, a vaccine procedure which is not the object of such campaigns will obviously not become part of popular culture. The result of this lack of information is that the population fails to utilize vaccines against such diseases as rubella, mumps, and hepatitis $\boldsymbol{B}$ or against Haemophilus influenza type $b$ and pneumococcus infections. We therefore argue for information on the existence and availability of these vaccines, so that not only the part of the population that has access to private medicine can benefit, but mainly so that pressure can be brought to bear on the government for all public health care services to supply them to the neediest portion of the population. We suggest that strategies for the socialization of immunoprophylatics should be defined with participation by all segments of society, incorporating measures such as the gradual expansion of the National Immunization Program, coverage of vaccine costs by health insurance policies, and granting of fiscal incentives to companies that vaccinate their employees and families. Finally, we propose a struggle against the prejudice surrounding participation by private initiative in collective health actions, as well as defense of the interaction between private and public sectors in all aspects of health throughout Brazil.

Key words: Vaccines; Public Health; Control Programs; Public Administration; Private Sector

A gravidade do quadro de saúde no Brasil pode ser facilmente avaliada, a partir dos números relativos às doenças transmissíveis que se caracterizam como as "grandes endemias" no país: oito milhões de indivíduos infectados pelo parasita causador da esquistossomose, outros seis milhões com a doença de Chagas e, provavelmente, um milhão de casos de malária por ano.

\footnotetext{
'Departamento de Imunologia. Instituto Oswaldo Cruz. Avenida Brasil, 4365, Cx. Postal 926, Rio de Janeiro, RJ, 21045-900, Brasil.
}

Temos cerca de 220 mil casos de Hanseníase com $5 \%$ de crescimento ao ano (somos o segundo país do mundo) e 80 a 100 mil de tuberculose a cada ano. A AIDS afetou a aproximadamente 60 mil brasileiros desde 1980, levando à morte mais de 22 mil deles. Estima-se que 30 mil crianças vão morrer vitimadas pela diarréia ou por infecções respiratórias no primeiro trimestre deste ano, só no nordeste.

Estes números não espantam a ninguém se levarmos em consideração que o Brasil é, segundo relatório recente do Banco Mundial, o penúltimo país do mundo em termos de distri- 
buição de renda (20\% da população mais rica concentra $68 \%$ do total de renda) e o sexagésimo terceiro em termos de mortalidade infantil (63 crianças mortas a cada mil nascidas vivas). As estimativas indicam que somos 32 milhões de malnutridos dos quais dois milhões de famintos, entre 15 e 20 milhões, vivendo abaixo da linha da miséria, 28 milhões de analfabetos! Cerca de $40 \%$ da população infantil tem baixo peso ao nascer. Temos dez mil menores abandonados, vivendo nas nossas ruas.

Estes dados nos permitem compreender a enorme expectativa de que o desenvolvimento de vacinas eficazes ajude ao menos a controlar algumas das doenças transmissíveis. Paradoxalmente, entretanto, vacinas eficientes e segures contra doenças infecto-contagiosas não menos graves estão disponíveis mas são sub-utilizadas.

Como não podia deixar de ser, é a parcela da população mais frágil e com maior risco de contrair e de ter complicações decorrentes destas doenças, que menos tem acesso a estes procedimentos simples que poderiam protegê-la. A razão é simples: algumas vacinas não estão incluídas no Programa Nacional de Imunizações (PNI), não são objeto de campanhas do governo e são, quase que sem exceção, oferecidas somente pela rede privada.

Uma reação fácil seria a de culpar o setor público por mais esta contradição brasileira. Mas, justiça seja feita, nesta área temos que reconhecer, mais do que a sua competência, a excelência do trabalho que vem sendo desenvolvido pela Fundação Nacional de Saúde (FNS), através do PNI, reduzindo drasticamente a prevalência de doenças como o tétano, a difteria, a coqueluche, o sarampo e a poliomielite. A cobertura vacinal média tem ficado em torno de $75 \%$ para todas as vacinas e é superior a $90 \%$, desde 1990, para a antipoliomielítica. Em decorrência disto, o último caso de isolamento do poliovírus selvagem ocorreu em março de 1989 na Paraíba e o Brasil recebeu da Organização Panamericana da Saúde (Opas), o certificado de erradicação da poliomielite em 1994.

Aqui, por razões quase inacreditáveis, os vilões são outros: a desinformação e o preconceito. Assim, mesmo as classes mais favorecidas, que poderiam se beneficiar da disponibilidade de tão nobres produtos, o fazem com freqüência desprezível.
Para entender um sistema que administra um PNI com competência ao mesmo tempo em que permite esta desinformação lesiva à população, temos que ter em mente que o governo é o maior formador de opinião nesta área através das campanhas de vacinação, que conduz e divulga exemplarmente. Portanto, um procedimento vacinal, que não seja objeto destas campanhas dificilmente fará parte da cultura popular que obviamente o ignorará.

É preciso não subestimar a fiação perfeitamente informada da comunidade médica que prescreve corretamente as vacinas não incluídas no PNI. Mas, a população que sequer ouviu falar de um procedimento, não tem como cobrar dos médicos a sua recomendação, deixando de exercer pressão para a atualização daqueles menos informados.

E o que custa esta desinformação? Não sabermos, por exemplo, que a hepatite $\mathrm{B}$, que pode provocar doença fulminante e câncer hepático e se transmite praticamente da mesma forma - embora seja mais contagiosa - que a AIDS, é evitável por uma vacina moderna, eficiente, segura e disponível? Não é difícil responder. Somos 300 milhões de portadores (assintomáticos ou com doença clinica) no mundo transmitindo ativamente a infecção. A Organização Mundial da Saúde (OMS) estima que um em cada cinco portadores morre prematuramente em função de cirrose hepática, um em cada 20 portadores morre prematuramente de câncer hepático e mais de dois milhões de indivíduos morrem anualmente em conseqüência da hepatite B. No Brasil, com 12 milhões de portadores, a Comissão Nacional de Hepatite recomendou a adoção de estratégias de proteção da população diferenciadas em função do grau de endemicidade da infecção no Estado. No Rio de Janeiro, onde estima-se que $2 \%$ da população esteja infectada, o que representa um contingente aproximado de 200 mil transmissores assintomáticos da doença, as medidas recomendadas são: vacinação sistemática obrigatória - integrada ao PNI - de menores de um ano, vacinação em campanhas de toda a população escolar de primeiro e segundo graus e vacinação de grupos de risco/ profissionais de saúde. Elas estão infelizmente longe de serem seguidas.

Todos nos lembramos, por exemplo, de que o Rio de Janeiro inteiro se alarmou recentemente com o aumento do número de casos de meningite 
por meningococo $\mathrm{B}$ e $\mathrm{C}$ que resultou na campanha de vacinação, cuja segunda etapa assistimos recentemente. O que poucos sabem é que as meningites por meningococo (A,B,C,Y ou W 135) são menos letais que as causadas por outras bactérias como o Haemophilus influenzae do tipo $b$ (Hib) e o pneumococo. A vacina contra o Hib, por exemplo, que não faz parte do PNI e só está disponível na rede privada, previne uma forma grave de meningite que acontece, independentemente das epidemias de meningite meningocócica, em torno de $95 \%$ das vezes em crianças de menos de cinco anos e em dois terços dos casos até os 15 meses de idade e é considerada "moralmente obrigatória" pelos muitos pediatras já esclarecidos da freqüência com que a doença é fatal ou deixa seqüelas irrecuperáveis em crianças saudáveis até então. No Brasil, segundo a FNS, de 1987 a 1991, 26,3\% dos casos de meningite de causa identificada em crianças de 0 a 12 meses foram causadas pelo $\mathrm{Hib}$ contra $25,8 \%$ dos casos atribuídos ao meningococo. A letalidade média dos casos de meningite por Hib no Instituto Estadual de Infectologia São Sebastião (IEISS-RJ) nos últimos cinco anos tem sido de $17 \%$ enquanto que a de doença meningocócica é de aproximadamente $10 \%$. No Rio de Janeiro, a letalidade foi de $15,1 \%$ de 1989 a 1991 e de $21,9^{\circ} \%$ considerando-se unicamente a faixa etária de 0 a 12 meses. No Brasil, a taxa de letalidade média, entre 1987 e 1991, foi de 17,6\% - 3,5 vezes superior à apresentada pelos países de primeiro mundo.

Quantos sabem que as doenças causadas pelo Streptocomus pneumoniae (pneumococo) permanecem uma importante causa de morbi-mortalidade principalmente em crianças, idosos e indivíduos com alguma condição de risco? Embora dados recentes no Brasil não sejam disponíveis, na Inglaterra, infecções por pneumococos são responsáveis por $34 \%$ das pneumonias que requerem hospitalização em adultos. Não obstante à alta sensibilidade de $90 \%$ dos S. pneumoniae à penicilina, a mortalidade por doenças pneumocócicas nos EUA tem sido considerada como sendo de $40 \%$ para doença bacterêmica e de $55 \%$ para meningite por pneumococo. No IEISS, a letalidade média para esta meningite nos últimos cinco anos é de 30\%. Pois bem, contra esta bactéria também existe uma vacina, licenciada desde 1983 nos EUA, onde já se demonstrou que os 23 sorotipos de S. pneumoniae utili- zados em sua preparação são responsáveis por $88 \%$ das doenças pneumocócicas nos EUA. No nosso meio, embora recomendada de forma absolutamente correta por alguns clínicos, ela é utilizada por uma fração ainda mínima dos que deveriam se beneficiar da disponibilidade de tal procedimento (idade > 65 anos, doenças cardiovasculares ou pulmonares, diabetes melitus, alcoolismo, cirrose, fístula liquórica, esplenectomia, anemia falciforme, doença de Hodgkin, linfomas, mieloma múltiplo, insuficiência renal crônica, síndrome nefrótica, transplantes, infecção sintomática ou assintomática por HIV). Entretanto sua eficácia não é objeto de nenhuma dúvida nos países onde foi estudada. A vacina reduz a incidência de infecção pneumocócica pelos sorotipos vacinais entre os casos de doenças bacterêmicas em $60 \%$ a $64 \%$ (EUA), a incidência da doença em indivíduos imunocompetentes de mais de 55 anos em 64\% a 70\% (EUA) e a incidência de pneumonia entre idosos residentes em asilos em 77\% (França) e entre indivíduos de mais de 65 anos (incluindo pessoas com doenças cardiovasculares ou pulmonares crônicas ou diabetes melitus) em $44 \%$ a $61 \%$ (CDC, Atlanta).

A vacina anti-sarampo tem sido objeto de campanhas vacinais do governo, atingindo $70 \%$ do seu público alvo. Recomendada a partir dos nove meses de idade pelo PNI, a imunização inclui reforços aos 15 meses e aos quatro anos. Quase que sistematicamente, crianças de classes média e alta tem estes reforços realizados com a vacina MMR (measles, mumps and rubella) que além do sarampo protege contra a caxumba e a rubéola. Usualmente uma doença benigna, a rubéola representa um enorme risco para o feto quando a mulher é infectada nos primeiros meses de gravidez, podendo causar malformações congênitas, aborto ou natimorto. A imunização antirubéola é, portanto, também um procedimento a ser praticado rotineiramente no atendimento médico geral e ginecológico de mulheres não-imunes, em idade fértil. A MMR deve ser utilizada prioritariamente sempre que houver igualmente susceptibilidade ao sarampo e/ou à caxumba. A caxumba se associa à encefalite (cinco casos em cada 1000 notificados, com mortalidade de $1,4 \%)$, surdez sensorioneural $(0,5$ a cinco casos por 100 mil notificados, mais comum em adultos), orquite (20 a 30\% dos casos em homens após a puberdade com atrofia testicular em 
$35 \%$ dos casos) e aborto espontâneo, quando a infecção ocorre no primeiro trimestre de gravidez. A maioria dos casos de caxumba ainda ocorre em crianças em idade escolar (cinco a 14 anos), reforçando a importância da introdução da MMR no calendário do PNI. Entretanto, com a honrosa exceção do estado de São Paulo, a MMR não é oferecida nos postos de saúde. Sem dúvida a mais conhecida das vacinas ignoradas pelo PNI, em clínicas privadas cariocas a MMR é responsável, junto com a anti-Haemophilus, por $50 \%$ das vacinas aplicadas contra os $30 \%$ que representam as que também são oferecidas pelo governo (BCG, Sabin, DPT, sarampo, ATT, DT e dT).

Enquanto não sabemos das vacinas eficazes que existem e estão disponíveis, ainda que só para uma das parcelas da população, nem esta poderá se beneficiar das propriedades protetoras destes produtos nem as outras, menos protegidas, poderão pressionar as autoridades governamentais para que todos os postos da rede pública passem a oferecé-las. Pior do que morrer por não poder se proteger é morrer por não saber que é possível proteger-se.

Mas como e quando saberemos? Se e quando as autoridades de saúde informarem. E podemos esperar que o governo o faça mesmo não realizando tais campanhas vacinais? Esta é de fato a questão central! Sim, podemos se o governo não tiver medo de assumir claramente a posição de divulgar as vacinas recomendáveis, independentemente de oferecê-las nos seus postos de vacinação. A OMS assume em seu Programa Ampliado de Imunização (PAI), que é responsabilidade dos governos promover vacinação da população alvo através de campanhas públicas para todas as doenças concernidas pelo PAI e para os casos de epidemias. O Brasil vem cumprindo à risca estas orientações e mais não faz por não ter condições ou por não priorizar a expansão do PNI, passando a oferecer gratuitamente vacinação para todas as doenças infectocontagiosas imunopreveníveis. Não precisa, entretanto, se colocar na situação desconfortável de considerar "esquizofrênica" a postura de informar sobre a existência de um procedimento recomendável, eficiente e seguro por não oferecê-lo rotineiramente na rede pública.

Mas a mudança deste quadro é possível. Não nos cabe nem pretendemos formular soluções mágicas e completas, mas gostaríamos de cha- mar a atenção para algumas iniciativas que julgamos potencialmente úteis para a alteração desta realidade.

Em primeiro lugar, lutemos por uma sociedade efetivamente participativa, buscando mecanismos para dar à população acesso a estes procedimentos. Empenhados em tal compromisso encontraríamos rapidamente saídas: expansão gradual do PNI dentro de um cronograma tornado público, cobertura de gastos com vacinação pelos seguros saúde, concessão de incentivos fiscais a empresas que garantissem a vacinação de seus funcionários e dos filhos destes... enfim não faltariam idéias criativas e factíveis.

Em segundo, é imprescindível que todos os segmentos da comunidade usem os veículos disponíveis para derrubar o preconceito contra a participação da iniciativa privada nas ações de saúde coletiva. Ainda que choque a muitos saber que uma vacina eficiente e necessária não esteja disponível nos postos públicos, é ainda mais dramático constatar que informar sobre sua existência e suas recomendações é, muitas vezes, considerado condenável. Desnecessário lembrar que esta informação passa a ser eticamente aceitável e politicamente correta quando e se o produto é oferecido pelo governo.

A "Cartilha de Procedimentos do PNI" (FNS), conceituou e definiu como "oportunidade perdida" toda circunstância de não-aproveitamento do encontro de um receptor potencial de uma vacina com este produto (por exemplo, uma gestante que procure atendimento médico por qualquer razão e deixe de ser informada da necessidade de fazer a prevenção do tétano neonatal). Assim, não seria correto que agíssemos da mesma forma para com as informações que concernem vacinas não oferecidas pelo estado? Uma mãe de uma criança de menos de cinco anos que procurasse informações sobre "vacina contra meningite", em qualquer estabelecimento público ou privado, não deveria sempre ser informada da necessidade imperiosa de proteger seu filho contra a infecção pelo $H i b$ ?

Finalmente temos que combater o preconceito que disfarça de ética a postura improdutiva de querer determinar papéis estanques para os atores do cenário da saúde coletiva, segundo a sua filiação aos setores público e privado. Como se o que contasse fossem os rótulos e não o conteúdo das ações, os partidos e não as ideolo- 
gias, os remédios e não a própria saúde. Como se defender a interação destes dois setores só devesse partir do setor privado e como se a resolução dos problemas de saúde pública pudesse prescindir da participação da enorme parcela da área de saúde que tramita fora dos domínios da administração pública.

Enquanto governo, laboratórios produtores e agentes de saúde não agirem juntos para que a população tome conhecimento da importância de todas as vacinas eficientes, seguras e disponíveis contra doenças infecto-contagiosas, estaremos perdendo tempo precioso no processo de busca de estratégias para socializar e expandir o uso destes instrumentos poderosos da medicina preventiva.

\section{AGRADECIMENTOS}

$\mathrm{O}$ autor agradece à Dra. Míriam Tendler pelas numerosas discussões durante a elaboração deste artigo, ao Dr. Renato Bello pelas informações concernentes às infecções por $H$. influenzae do tipo b, N. meningitidis e $S$. pneumoniae no Instituto Estadual de Infeetologia São Sebastião e às Dras. Helen Freitas (Fundação Nacional de Saúde) e Mary Baran (Secretaria Municipal de Saúde) pelos dados referentes às meningites no Brasil e no estado do Rio de Janeiro, respectivamente. A bibliografia está a disposição dos interessados com o autor.

\section{RESUMO}

\section{DANIEL-RIBEIRO, C. T. Vacinas: Negócio de}

Estado? Cad. Saúde Públ., Rio de Janeiro, 11 (1): 137-141, jan/mar, 1995.

Ainda que a expectativa de que o desenvolvimento de vacinas eficazes ajude a controlar algumas das doenças transmissíveis responsáveis pelas "grandes endemias" no nosso país, vacinas eficientes e seguras contra doenças infecto-contagiosas não menos graves estão disponíveis, mas são subutilizadas. A razão é simples: algumas vacinas não estão incluídas no Programa Nacional de Imunização (PNI), não sendo, portanto, objeto de campanhas do governo.
Apesar da competência com a qual a Fundação Nacional de Saúde (FNS), através do PNI, atua reduzindo a prevalência de doenças como a difteria, coqueluche, sarampo e poliomielite, a desinformação e o preconceito tornam várias vacinas inacessíveis à uma parcela importante da população. Por ser o governo - através de suas campanhas de vacinação - o maior formador de opinião nesta área, um procedimento vacinal que não seja objeto destas campanhas não fará parte obviamente da cultura popular. Esta desinformação faz com que a população deixe de utilizar vacinas como a anti-nrbéola, a anticaxumba, a antihepatite $\mathrm{B}$, a anti-Haemophylus influenza do tipo b e a antipneumocócica, cujas indicações detalhamos no artigo. Assim defendemos a informação da existência e da disponibilidade destas vacinas não só para que a parcela da população que tem acesso à medicina privada possa se beneficiar, mas sobretudo para que se exerça pressão sobre o governo para que todos os postos de saúde passem a oferecê-las à população mais carente. Sugerimos, ainda, que a definição de estratégias de socialização dos imunoprofiláticos seja feita com a participação de todos os segmentos da sociedade, buscando medidas como a expansão gradual do PNI, a cobertura de gastos com vacinas pelos seguros saúde e a concessão de estímulos fiscais a empresas que vacinem empregados e filhos destes. Propomos, finalmente, o combate aos preconceitos contra a participação da iniciativa privada nas ações de saúde coletiva e contra a defesa da interação entre os setores público e privado por todos os atores do cenário da saúde no país.

Palavras-Chave: Vacinas; Saúde Pública; Programas de Controle; Administração Pública; Setor Privado 